Original article

\title{
EFFECTS OF DIETARY SUPPLEMENTATION OF NETTLE ROOT EXTRACT AND PUMPKIN SEED OIL ON PRODUCTION TRAITS AND INTESTINAL MICROFLORA IN BROILER CHICKENS
}

\author{
M. ABOUHOSSEINI TABARI ${ }^{1}$, KH. GHAZVINIAN ${ }^{2}$, M. $_{\text {IRANI }}^{3} \&$ R. MOLAEI ${ }^{3}$ \\ ${ }^{1}$ Faculty of Veterinary Medicine, Amol University of Special Modern \\ Technologies, Amol, Iran; ${ }^{2}$ Department of Clinical Sciences, Faculty of \\ Veterinary Medicine, Semnan University, Semnan, Iran; ${ }^{3}$ Islamic Azad \\ University, Quaemshahr-Branch, Quaemshahr, Iran
}

\begin{abstract}
Summary
Abouhosseini Tabari, M., Kh. Ghazvinian, M. Irani \& R. Molaei, 2016. Effects of dietary supplementation of nettle root extract and pumpkin seed oil on production traits and intestinal microflora in broiler chickens. Bulg. J. Vet. Med., 19, No 2, 108-116.

Herbal substances can be used as natural growth performance enhancers in poultry nutrition instead of antibiotics. This study was conducted to evaluate the effect of nettle root and pumpkin seed on production traits and intestinal microflora of broiler chickens. A total of 120 day-old Ross 308 male broilers were randomly allocated into 4 groups: 1) CON, receiving basal diet, 2) PSO, basal diet +0.5 $\mathrm{g} / \mathrm{kg}$ pumpkin oil, 3) NRE, basal diet $+0.5 \mathrm{~g} / \mathrm{kg}$ nettle extract and 4) NEPO, basal diet $+0.5 \mathrm{~g} / \mathrm{kg}$ nettle extract $+0.5 \mathrm{~g} / \mathrm{kg}$ pumpkin oil. Body weight and feed intake were measured weekly and feed conversion ratio was calculated. On day 42 , eight birds per treatment group were randomly selected for ileal bacterial counts and 12 birds for determination of carcass and organ weights. NEPO birds had the highest body weight and CON had the lowest at 21 and 42 days of age. Significant increase was noticed in feed intake in NRE and NEPO birds between 22-42 days of age. Nettle root and pumpkin oil addition improved overall feed conversion ratio. Effects of dietary treatments on carcass weight, portion yield and the relative weights of the heart, spleen, liver and gizzard were insignificant except for thigh, drumstick and bursa. The lowest Escherichia coli and the highest Lactobacillus counts were observed in NEPO and NRE birds $(\mathrm{P}=0.0001)$. The results of present study suggest that supplementation with nettle root and pumpkin oil, particularly their combination has a positive impact on broiler chickens.
\end{abstract}

Key words: broilers, carcass yield, ileal bacterial count, growth performance, nettle root extract, pumpkin seed oil

\section{INTRODUCTION}

Modern intensive poultry production has achieved great gains in the production of high quality safe chicken meat and eggs.
The use of feed additives has been an important part of achieving this success. Antimicrobials and antioxidants are com- 
mon feed additives used in poultry diets (Hashemi et al., 2012). Phytogenics are a relatively new generation of feed additives. Biologically active constituents of herbs possess many beneficial properties. The growth performance can be affected by herbal substances in some ways: (i) their significant antibacterial effect can suppress pathogenic microflora in the gastrointestinal tract; (ii) they can improve the taste and smell of feed and influence the feed intake of poultry; (iii) they can stimulate appetite and digestion (Petrovic et al., 2011). Many researchers tried to use herbal substances as natural growth performance enhancers in poultry nutrition instead of the antibiotic growth promoters which are banned in many countries (Botsoglou et al., 2002; 2004; Alcicek et al., 2003; 2004; Jang et al., 2008).

Pumpkin has been considered beneficial to health because it contains various biologically active components such as polysaccharides, p-aminobenzoic acid, fixed oils, sterols, proteins and peptides (Yadav et al., 2010). Pumpkin oil has antimicrobial components and is effective against a lot of bacteria. Several in vitro studies reported significant antibacterial and antifungal properties of pumpkin seed oil (Vassiliou et al., 1998; Hammer et al., 1999; Xiong et al., 2000; Ng et al., 2002).

Urtica L. (stinging nettle) distinguished with stinging hairs, is an annual and perennial herb. It is consumed for a long time as medicinal plant in many parts of the world. Steroids, polysaccharides, terpenoids, coumarins, phenylpropanoids and lectins have been isolated from its roots (Yener et al., 2009). Polysaccharides isolated from the aqueous root extracts of nettle stimulate T-lymphocytes or the complement system in vitro (Wagner et al., 1989). It is reported that nettle prevents the damage of rat liver tissue (Turk- dogan et al., 2003) and has powerful antioxidant activity (Gulcin et al., 2004).

Although numerous in vitro studies have demonstrated beneficial properties of these herbal plants, there is still insufficient in vivo research especially in the field of poultry husbandry. The objective of present study was to examine the effect of pumpkin seed oil and nettle root extract supplementation on broiler chicken performance, carcass traits and to assess their effects on ileal microflora.

\section{MATERIALS AND METHODS}

\section{Herbal supplements preparation}

Urtica L. (nettle) was collected from the Mazandaran province, north of Iran. The plant was identified and authenticated by Sari University of Agricultural sciences and Natural Resources, Mazandaran Province, Iran. Nettle roots were washed and dried, then subjected to hydro-alcoholic extraction with methanol and water (1:1). The extract under reduced pressure was evaporated, dried and stored at $4^{\circ} \mathrm{C}$ till further use. Pumpkin seeds were provided by Sari University of Agricultural Sciences and Natural Resources, Mazandaran Province, Iran. The seeds were dried at $75^{\circ} \mathrm{C}$ for $24 \mathrm{~h}$ and then grounded into powder. Ten grammes of ground pumpkin seeds were extracted in a Soxhlet extractor with $100 \mathrm{~mL}$-hexane at $90^{\circ} \mathrm{C}$ for $6 \mathrm{~h}$, as described in the Soxhlet standard extraction method (AOAC, 1995). The n-hexane was removed under reduced pressure by using a rotary evaporator and the oil was dried in a drying oven at $105^{\circ} \mathrm{C}$. The recovered oil was stored at $4^{\circ} \mathrm{C}$ until use.

Experimental design, diets and housing

A total of 120 day-old Ross-308 male broilers were used in this study. The 
Effects of dietary supplementation of nettle root extract and pumpkin seed oil on production traits ....

broiler chickens were randomly allocated into 4 groups, a control group and 3 experimental groups (30 in each). Each of the 4 dietary treatments contained 3 replicates of 10 chicks each. A basal diet (Table 1) was given to broiler chickens in the control group (Group CON). The remaining 3 groups were given the same basal diet, further supplemented with either pumpkin seed oil, nettle root extract or combination of them from day 1 to the last day of the experiment. Pumpkin seed oil was added at $0.5 \mathrm{~g} / \mathrm{kg}$ to the diets (Group PSO), and nettle root extract at $0.5 \mathrm{~g} / \mathrm{kg}$ (Group NRE). The diet of NEPO group was supplemented simultaneously with $0.5 \mathrm{~g} / \mathrm{kg}$ nettle root extract and $0.5 \mathrm{~g} / \mathrm{kg}$ pumpkin seed oil.

\section{Performance parameters}

Chickens of each pen were weighed every week of the experiment. During the experiment, feed intake (FI) for each pen was recorded and feed conversion ratio
(FCR) was calculated by dividing feed intake to weight gain. At the end of the experiment on day 42, eight birds were randomly selected per treatment group and were individually weighed to ascertain if they represented the average group weight. Birds were then fasted for $8 \mathrm{~h}$ with water offered ad libitum, and were reweighted before they were sacrificed. After bleeding, scalding, plucking and washing, the feet, head and neck were removed. Thereafter the carcasses were eviscerated manually, cutting the neck and through the respiratory system; and removing the esophagus. The gizzards as well as the visceral organs (liver, heart, spleen, and bursa) were removed by hand through an incision made around the sternum. Cutting on the joints, the carcasses were cut into drumsticks (legs), wings and thighs; and through the shoulder area to remove backbone from breast as prescribed by Nkukwana et al. (2014). Visceral organs and cuts were then weighed

Table 1. Composition of the basal diets given to the broilers throughout the experiment

\begin{tabular}{lccc}
\hline & $\begin{array}{c}\text { Starter } \\
(0-21 \text { days })\end{array}$ & $\begin{array}{c}\text { Grower } \\
(22-35 \text { days })\end{array}$ & $\begin{array}{c}\text { Finisher } \\
(36-49 \text { days })\end{array}$ \\
\hline Ingredients (\%) & & & \\
Maize & 57.84 & 58.69 & 61.40 \\
Soya bean & 36.65 & 35.30 & 31.48 \\
Fat & 1.60 & 2.20 & 3.17 \\
Limestone & 1.26 & 1.24 & 1.09 \\
Dicalcium phosphate & 1.56 & 1.30 & 1.15 \\
Vitamin-mineral premix & 0.50 & 0.50 & 0.50 \\
NaCl & 0.20 & 0.25 & 0.30 \\
L-lysine & 0.04 & 0.07 & 0.07 \\
DL-methionine & 0.20 & 0.25 & 0.20 \\
Sodium bicarbonate & 0.10 & 0.15 & \\
Nutrient level (\%) & & & 3050 \\
Metabolisable energy (kcal/kg) & 2900 & 2950 & 19.00 \\
Crude protein & 21.00 & 20.50 & 0.34 \\
Available phosphorus & 0.42 & 0.37 & 0.50 \\
Methionine & 0.52 & 0.48 & 1.10 \\
Lysine & 1.30 & 1.10 & \\
\hline
\end{tabular}


Table 2. The effect of pumpkin seed oil, nettle root extract and their combination on broiler chickens performance

\begin{tabular}{|c|c|c|c|c|}
\hline & \multicolumn{4}{|c|}{ Treatments } \\
\hline & $\mathrm{CON}$ & PSO & NRE & NEPO \\
\hline \multicolumn{5}{|c|}{ Body weight (g) } \\
\hline Day 1 & $41.6 \pm 0.2$ & $40.3 \pm 0.23$ & $42.1 \pm 0.3$ & $40.5 \pm 0.35$ \\
\hline Day 21 & $892.0 \pm 3.3^{\mathrm{a}}$ & $912.2 \pm 2.1^{\mathrm{a}}$ & $918.8 \pm 2.1^{\mathrm{a}}$ & $930.1 \pm 3.3^{\mathrm{b}}$ \\
\hline Day 42 & $2277.7 \pm 5.2^{\mathrm{a}}$ & $2286.8 \pm 9.1^{\mathrm{a}}$ & $2324.1 \pm 11.8^{\mathrm{b}}$ & $2428.2 \pm 4.6^{\mathrm{c}}$ \\
\hline \multicolumn{5}{|c|}{ Feed intake (g/day) } \\
\hline Day $1-21$ & $1022.4 \pm 12.3$ & $1032.6 \pm 14.4$ & $1045.7 \pm 15.5$ & $1055.5 \pm 14.6$ \\
\hline Day $22-42$ & $1646.4 \pm 5.6^{\mathrm{a}}$ & $1688.2 \pm 4^{\mathrm{ab}}$ & $1700.3 \pm 6.6^{\mathrm{b}}$ & $1760.8 \pm 11.2^{\mathrm{c}}$ \\
\hline Day $1-42$ & $1095.3 \pm 14.6$ & $1098.5 \pm 10.3$ & $1117.6 \pm 12.4$ & $1124.6 \pm 5.6$ \\
\hline \multicolumn{5}{|c|}{ Feed conversion ratio (feed/gain) } \\
\hline Day $1-21$ & $1.23 \pm 0.06$ & $1.25 \pm 0.01$ & $1.23 \pm 0.02$ & $1.24 \pm 0.01$ \\
\hline Day $22-42$ & $1.91 \pm 0.02^{\mathrm{a}}$ & $1.80 \pm 0.01^{\mathrm{a}}$ & $1.85 \pm 0.03^{\mathrm{a}}$ & $1.74 \pm 0.01^{\mathrm{b}}$ \\
\hline Day $1-42$ & $1.85 \pm 0.005^{\mathrm{a}}$ & $1.73 \pm 0.02^{\mathrm{a}}$ & $1.65 \pm 0.007^{\mathrm{b}}$ & $1.63 \pm 0.007^{\mathrm{b}}$ \\
\hline
\end{tabular}

CON: basal diet; PSO: basal diet supplemented with $0.5 \mathrm{~g} / \mathrm{kg}$ pumpkin seed oil; NRE: basal diet supplemented with $0.5 \mathrm{~g} / \mathrm{kg}$ nettle root extract; NEPO: basal diet supplemented with $0.5 \mathrm{~g} / \mathrm{kg}$ pumpkin seed oil and nettle root extract. Means within a row with no common letter(s) differ significantly $(\mathrm{P}<0.05)$.

individually; and yields were calculated and expressed as percentages of live weight. Animal care followed the official guidelines and protocol of the study was approved by Ethics Committee of Islamic Azad University, Quaemshahr branch, Iran.

\section{Enumeration of bacteria}

On day 42, eight birds from each group of broilers were chosen at random. Their alimentary tracts were immediately dissected after slaughter, and the ileal contents were gently squeezed and collected into Falcon tubes. The collected contents were kept on ice until inoculation and incubation. All samples with normal saline solution were serially diluted $\left(10^{-7}\right.$ to $10^{-9}$ ) and plated on agar plates. Escherichia coli was counted on the eosin- methylene blue agar medium (SigmaAldrich, Germany). Plates were incubated for $24 \mathrm{~h}$ at $37^{\circ} \mathrm{C}$. Colonies characterised with green metallic surface sheen colour were considered to be E. coli. Lactobacillus was quantified on the Rogosa agar medium (Fluka, Germany). Plates were incubated in an anaerobic jar at $37^{\circ} \mathrm{C}$ for 48-72 h. Characteristic white colonies on Rogosa plates were recognised as Lactobacillus. The results of the microbiological analyses were transformed to $\log 10$.

\section{Statistical analysis}

Statistical analyses were conducted using the general linear models procedure of SAS software (SAS Institute, 2005). When significant effect was revealed, the differences between dietary treatment means were separated by Duncan's multi- 
ple range tests. Bacterial numbers were converted to log colony-forming units for statistical analysis. All statements of significance were based on $\mathrm{P}<0.05$.

\section{RESULTS}

The average body weight $(\mathrm{BW})$ at 1,21 and 42 days of age; feed intake and feed conversion ratio (FCR) for the periods 0 to 21 days and 22 to 42 days are presented in Table 2 .

Broiler chickens in NEPO group had the highest $\mathrm{BW}$ on day 21 and 42 $(\mathrm{P}<0.05)$; while CON had the lowest. Significant increase in body weight was observed in NRE compared to $\mathrm{CON}$ and PSO groups. However there was no significant difference in the total feed consumption of different treatment groups but herbal supplementation affected feed intake from day 22 to 42 . NEPO birds had the highest feed intake in this period $(\mathrm{P}<0.05)$. The nettle root extract and combination of nettle root extract and pump- kin seed oil supplementation improved overall FCR ( $\mathrm{P}=0.0001)$. The FCR of the NRE and NEPO broilers was better than that of the CON and PSO groups. The control group had the poorest FCR.

Table 3 shows the effect of dietary treatments on chilled carcass weight, portion yield and the relative weights of the liver, gizzard, heart, spleen and bursa. Visceral and digestive organs size showed no significant difference between treatments except for the heart. Breast and wing weights had no significant difference among treatment groups but for thigh and drumstick, a statistical difference was present. The highest thigh percentage was seen in NEPO and NRE birds while the lowest was in CON birds. Drumstick weight in NEPO birds was statistically higher than all of others $(\mathrm{P}<0.05)$. No significant differences observed among dietary treatments in liver, gizzard, heart and spleen weights.

The results of the bacterial counts in ileum are shown in Table 4 . The E. coli

Table 3. Effects of nettle root extract and pumpkin seed oil supplementation on carcass yields and digestive tract characteristics

\begin{tabular}{lcccc}
\hline \multirow{2}{*}{$\begin{array}{l}\text { Chilled carcass } \\
\text { yield, \% BW }\end{array}$} & \multicolumn{4}{c}{ Treatments } \\
\cline { 2 - 5 } & CON & PSO & NRE & NEPO \\
\hline Breast & $62.10 \pm 2.10$ & $62.80 \pm 2.30$ & $63.20 \pm 1.90$ & $64.80 \pm 3.10$ \\
Thigh & $24.80 \pm 0.10$ & $25.20 \pm 0.32$ & $25.40 \pm 0.20$ & $26.10 \pm 0.33$ \\
Wing & $14.40 \pm 0.20^{\mathrm{a}}$ & $14.70 \pm 0.13^{\mathrm{a}}$ & $15.80 \pm 0.10^{\mathrm{b}}$ & $15.60 \pm 0.30^{\mathrm{b}}$ \\
Drumstick & $7.10 \pm 0.33$ & $6.80 \pm 0.24$ & $6.90 \pm 0.54$ & $7.00 \pm 0.10$ \\
Liver & $7.90 \pm 0.07^{\mathrm{a}}$ & $7.50 \pm 0.09^{\mathrm{a}}$ & $7.60 \pm 0.10^{\mathrm{a}}$ & $9.20 \pm 0.04^{\mathrm{b}}$ \\
Gizzard & $2.05 \pm 0.80$ & $2.20 \pm 1.02$ & $2.21 \pm 0.53$ & $2.30 \pm 0.66$ \\
Heart & $1.16 \pm 0.33$ & $1.12 \pm 0.23$ & $1.14 \pm 0.16$ & $1.17 \pm 0.25$ \\
Spleen & $0.37 \pm 0.06^{\mathrm{a}}$ & $0.47 \pm 0.02^{\mathrm{b}}$ & $0.51 \pm 0.08^{\mathrm{b}}$ & $0.41 \pm 0.02^{\mathrm{a}}$ \\
Bursa & $0.10 \pm 0.05$ & $0.09 \pm 0.01$ & $0.09 \pm 0.01$ & $0.08 \pm 0.02$ \\
\hline
\end{tabular}

CON: basal diet; PSO: basal diet supplemented with $0.5 \mathrm{~g} / \mathrm{kg}$ pumpkin seed oil; NRE: basal diet supplemented with $0.5 \mathrm{~g} / \mathrm{kg}$ nettle root extract; NEPO: basal diet supplemented with $0.5 \mathrm{~g} / \mathrm{kg}$ pumpkin seed oil and nettle root extract. Means within a row with no common letter(s) differ significantly $(\mathrm{P}<0.05)$. 
Table 4. Effects of nettle root extract and pumpkin seed oil supplementation on count of microflora expressed as $\log 10$ colony-forming units per gram $(\mathrm{CFU} / \mathrm{g})$ in the ileum of broilers

\begin{tabular}{lcccc}
\hline \multirow{2}{*}{$\begin{array}{l}\text { Microbial counts } \\
\text { (CFU/g) }\end{array}$} & \multicolumn{4}{c}{ Treatments } \\
\cline { 2 - 5 } & CON & PSO & NRE & NEPO \\
\hline Escherichia coli & $7.51 \pm 0.10^{\mathrm{a}}$ & $7.02 \pm 0.02^{\mathrm{b}}$ & $6.61 \pm 0.26^{\mathrm{c}}$ & $6.42 \pm 0.12^{\mathrm{c}}$ \\
Lactobacillus & $7.72 \pm 0.05^{\mathrm{a}}$ & $8.17 \pm 0.33^{\mathrm{a}}$ & $8.59 \pm 0.06^{\mathrm{b}}$ & $8.79 \pm 0.08^{\mathrm{b}}$ \\
\hline
\end{tabular}

CON: basal diet; PSO: basal diet supplemented with $0.5 \mathrm{~g} / \mathrm{kg}$ pumpkin seed oil; NRE: basal diet supplemented with $0.5 \mathrm{~g} / \mathrm{kg}$ nettle root extract; NEPO: basal diet supplemented with $0.5 \mathrm{~g} / \mathrm{kg}$ pumpkin seed oil and nettle root extract. Means within a row with no common letter(s) differ significantly $(\mathrm{P}<0.05)$.

count in control group was higher than the other groups while in NRE and NEPO birds it was lower than in the other birds $(\mathrm{P}<0.05)$. The lowest Lactobacillus count was noted in CON group as compared with other groups. Dietary pumpkin seed oil and nettle root supplementation increased the Lactobacillus count in NRE and NEPO birds $(\mathrm{P}<0.05)$ however this increase in PSO birds was not statistically significant $(\mathrm{P}>0.05)$.

\section{DISCUSSION}

Due to cross-resistance against pathogens and residues, investigators are seeking alternatives to antibiotics as growth enhancers in poultry industry. Phytogenics are a relatively new class of feed additives. The exact mode of action by which plant bioactive substances exert their positive effects on bird performance is not well understood. Nevertheless, it is speculated that the main site of activity is within the gastrointestinal tract by modification of gut microflora, maximising both feed digestibility and growth rate (Nkukwana et al., 2014).

In the present study, although broilers overall feed intake was not increased in herbal supplemented diets, body weight was significantly increased in birds fed diets supplemented with nettle extract and pumpkin oil. The current study findings indicate that NEPO and NRE birds had significantly better FCR compared to the control treatment. The better FCR in these groups was due to higher body weight gain, lower feed intake or improved conditions of intestine leading to better digestion, absorption and utilisation of nutrients. As seen from Table 4, the herbal supplementation was closely associated to the reduced number of ileal $E$. coli counts. The antimicrobial effect of pumpkin seed oil has been well documented (Vassiliou et al., 1998; Xiong, 2000). Hammer et al. (1999) showed that pumpkin oil inhibits Acinetobacter baumanii, Aeromonas veronii biogroup sobria, Candida albicans, Enterococcus faecalis, Escherichia coli, Klebsiella pneumoniae, Pseudomonas aeruginosa, Salmonella enterica subsp. enterica serotype Typhimurium, Serratia marcescens and Staphylococcus aureus (Hammer et al. 1999). Gulçin et al. (2004) found some antimicrobial activity of $U$. dioica against E. coli, Enterobacter aerogenes, S.epidermidis and Candida albicans. Modarresi-Ghahardehi et al. (2012) suggested from the findings of their study that nettle extracts can be used a potential source of natural antimicrobial compound. Results shown in Table 3 indicate that chilled carcass weight and rela- 
tive weights of the gizzard, liver, pancreas and spleen of broilers were not affected by dietary treatments except for the heart. Positive correlations have been reported between the heart and the carcass traits, suggesting that as carcass yield increases, the heart weight also increases (McEntee et al., 2001). Relative weights of the immune organs, bursa of Fabricius and spleen, were not significantly different between treatment groups. In the present study, the breast muscle weights were not different among treatments, but the addition of nettle root extract and pumpkin seed oil in NRE and NEPO birds increased significantly the thigh and drumstick weights. Although it was not observed in the current study, it has been reported that herbal supplementation enhanced the eviscerated breast muscle proportion (Jamroz et al., 2005).

On the other hand, Basmacioglu et al. (2004) and Sarica et al. (2005) found no beneficial effect of dietary herbal supplementation on the carcass yield of broiler chickens. Celic et al. (2011) suggested that pumpkin seed oil can be added to the diet of layers without altering the growth and laying performance in order to produce eggs enriched in unsaturated acids and low in cholesterol.

Positive role of medicinal plants on keeping a balanced microbial ecosystem in the digestive tract and stimulating digestive enzymes secretions increase nutrient digestion and lead to better body weight gain (Ramakrishna et al., 2003). Studies carried out in the past years on the use of medicinal herbs in broiler feeds have been extensive. All groups that received herbal supplementation had better results than the control group. Improved weight gain and FCR in present study could be probably due to the positive role of these herbs on keeping a balanced microflora in the digestive tract.

In conclusion, the present study showed that the combination of nettle root and pumpkin seed oil had a positive impact on FCR, body weight and thigh and drumstick weight and was also capable of playing an essential role in the health of poultry by maintaining a balanced microflora in the digestive system.

\section{REFERENCES}

Alcicek, A., M. C. Bozkurt \& M. Abuk, 2003. The effect of essential oil combination derived from selected herbs growing wild in Turkey on broiler performance. South African Journal of Animal Sciences, 33, 89-94.

Alcicek, A., M. C. Bozkurt \& M. Abuk, 2004. The effect of a mixture of herbal essential oils, an organic acid or a probiotics on broiler performance. South African Journal of Animal Sciences, 34, 217-222.

AOAC, 1995. Official Methods of Analysis, $7^{\text {th }}$ edn, AOAC, Washington, DC.

Basmacioglu, H., Ö. Tokusoglu \& M. Ergül, 2004. The effect of oregano and rosemary essential oils or alpha-tocopheryl acetate on performance and lipid oxidation of meat enriched with n-3 PUFA's in broilers. South African Journal of Animal Science, 34, 197-210.

Botsoglou, N. A., P. Florou-Paneri, E. Christaki, D. Fletouris \& A.B. Spais, 2002. Effect of dietary oregano essential oil on performance of chickens and on iron-induced lipid oxidation of breast, thigh, and abdominal fat tissues. British Poultry Science, 43, 223-230.

Botsoglou, N. A., E. Christaki, P. FlorouPaneri, I. Giannenas, G. Papageorgiou \& A. B. Spais, 2004. The effect of a mixture of herbal essential oils or $\alpha$-tocopheryl acetate on performance parameters and oxidation of body lipid in broilers. South 
African Journal of Animal Science, 34, $52-61$.

Celik, L., H. R. Kutlu, Z. Sahan, A. B. Kiraz, U. Serbester, A. Hesenov \& A. Tekeli, 2011. Dietary inclusion of pumpkin seed oil for a cholesterol low and oleic and linolenic acid rich egg production in layer hens. Revue de Médecine Vétérinaire, 162, 126-132.

Gulcin, I, O. I. Kufrevioglu, M. Oktay \& M. E. Buyukokuroglu, 2004. Antioxidant, antimicrobial, antiulcer and analgesic activities of nettle (Urtica dioica L). Journal of Ethnopharmacology, 90, 205-215.

Hammer, K. A., C. F. Carson \& T. V. Riley, 1999. Antimicrobial activity of essential oils and other plant extracts. Journal of Applied Microbiology, 86, 985-990.

Hashemi, S. R., I. Zulkiflib, H. Davoodic, Z. Zunitad \& M. Ebrahimie, 2012. Growth performance, intestinal microflora, plasma fatty acid profile in broiler chickens fed herbal plant (Euphorbia hirta) and mix of acidifiers. Animal Feed Science and Technology, 178, 167-174.

Jamroz, D., A. Wiliczkiewicz, T. Wertelecki, J. Orda \& J. Skorupińska, 2005. Use of active substances of plant origin in chicken diets based on maize and locally grown cereals. British Poultry Science, 46, 485493.

Jang, A., X. D. Liu, M. H. Shin, B. D. Lee, S. K. Lee, J. H. Lee \& C. Jo, 2008. Antioxidative potential of raw breast meat from broiler chicks fed a dietary medicinal herb extract mix. Poultry Sciences, 87, 23822389.

Mc Entee, G. M., K. A. Rance \& R. M. McDevitt, 2001. Genetics of support organ morphology: Assessment of heritability and correlation values in a single line of broiler chicken. British Poultry Science, 42(S1), 121-122.

Modarresi-Chahardehi, A., D. Ibrahim, S. Sh. Fariza \& L. Mousavi, 2012. Screening antimicrobial activity of various extracts of Urtica dioica. Revista de Biología Tropical, 60, 1567-1576.
Ng T. B., A. Parkash \& W. W. Tso, 2002. Purification and characterization of moschins, arginine-glutamate-rich proteins with translation inhibiting activity from brown pumpkin (Cucurbita moschata) seeds. Protein Expression and Purification, 26, 9-13.

Nkukwana T. T., V. Muchenje, E. Pieterse, P. J. Masika, T. P. Mabusela, L. C. Hoffman \& K. Dzama, 2014. Effect of Moringa oleifera leaf meal on growth performance, apparent digestibility, digestive organ size and carcass yield in broiler chickens. Livestock Science, 161, 139-146.

Petrovic, V., S. Marcincak, P. Popelka, J. Simkova, M. Martonova, J. Buleca, D. Marcincakova, M. Tuckova, L. Molnar \& G. Kovac, 2011. The effect of supplementation of clove and agrimony or clove and lemon balm on growth performance, antioxidant status and selected indices of lipid profile of broiler chickens. Journal of Animal Physiology and Animal Nutrition, 96, 970-977.

Ramakrishna, R. R., K. Platel \& K. Srinivasan, 2003. In vitro influence of spices and spice-active principles on digestive enzymes of rat pancreas and small intestine. Nahrung, 47, 408-412.

Sarica, S., A. Ciftci, E. Demir, K. Kilinc \& Y. Yildirim, 2005. Use of antibiotic growth promoter and two herbal natural feed additives with and without exogenous enzymes in wheat based broiler diets. South African Journal of Animal Science, 35, 61-72.

Turkdogan, M. K., H. Ozbek, Z. Yener, I. Tuncer, I. Uygan \& E. Ceylan, 2003. The role of Urtica dioica and Nigella sativa in the prevention of carbon tetrachloride induced hepatotoxicity in rats. Phytotherapy Research, 17, 942-946.

Vassiliou, A. G., G. M. Neumann, R. Condron \& G. M. Polya, 1998. Purification and mass spectrometry assisted sequencing of basic antifungal proteins from seeds of pumpkin (Cucurbita maxima). Plant Science, 134, 141-162. 
Effects of dietary supplementation of nettle root extract and pumpkin seed oil on production traits ....

Xiong, X. M., 2000. Study on extraction and separation of effective composition of pumpkin polysaccharide and its glucatonic effect. Chinese Traditional Patent Medicine, 22, 563-565.

Yadav, M., S. Jain, R. Tomar, K. S. G. B. Prasad \& H. Yadav, 2010. Medicinal and biological potential of pumpkin: An updated review. Nutrition Research Reviews, 23, 184-190.

Yener, Z., I. Celik, F. Ilhan \& R. Bal, 2009. Effects of Urtica dioica L. seed on lipid peroxidation, antioxidants and liver pathology in aflatoxin-induced tissue injury in rats. Food and Chemical Toxicology, 47, 418-424.

Wagner, H., F. Willer \& B. Kreher, 1989. Biologically active compounds from the aqueous extract of Urtica dioica. Planta Medica, 55, 452-454.
Paper received 20.11.2014; accepted for publication 22.01.2015

\section{Correspondence:}

Khosro Ghazvinian

Department of Clinical Sciences,

Faculty of Veterinary Medicine,

Semnan University, Semnan, Iran; tel: +982323664892; fax: +982323664894;

e-mail: khghazvinian@semnan.ac.ir 